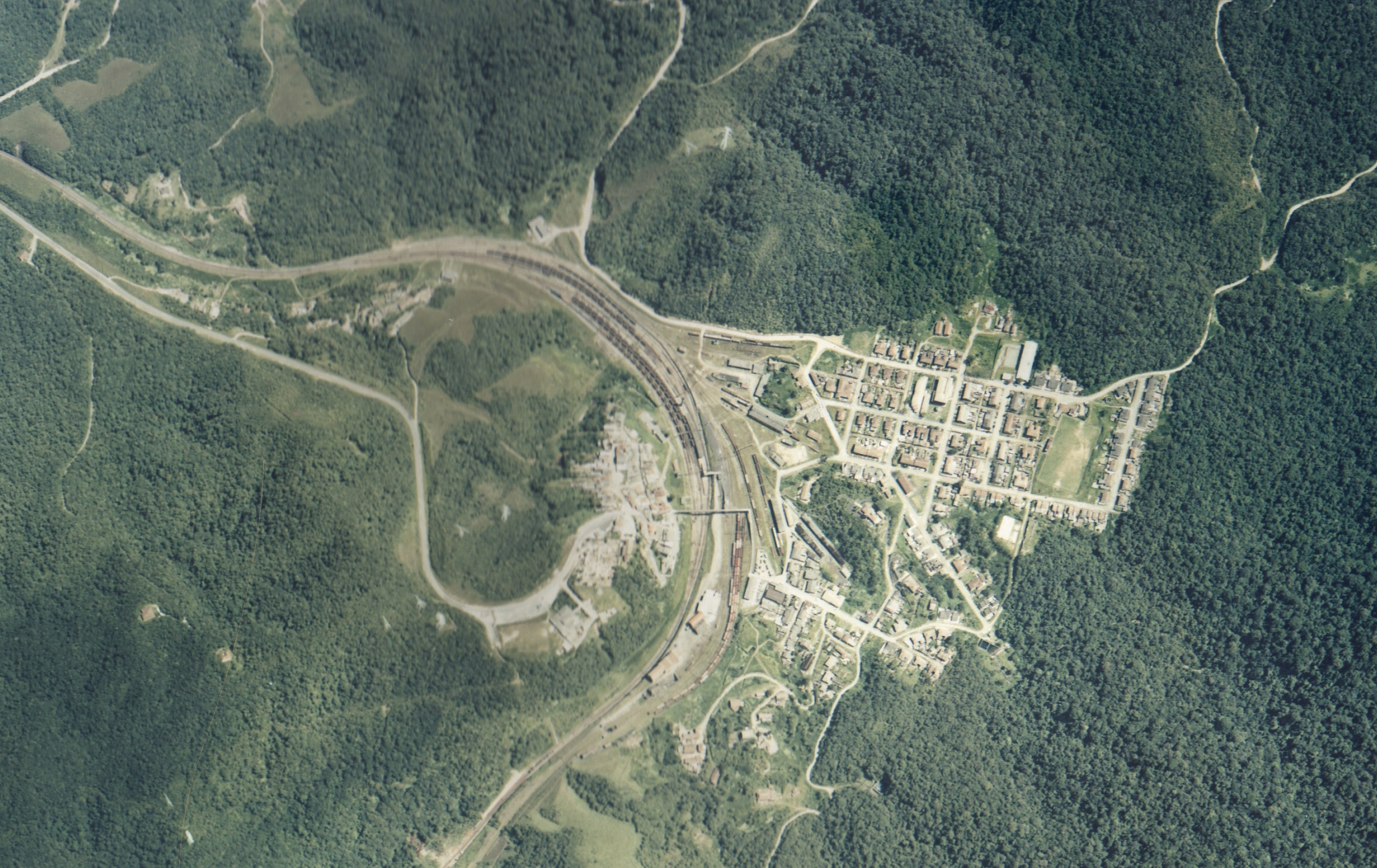




\section{PAISAGEM CULTURAL DE PARANAPIACABA: UMA EXPERIÊNCIA DE GESTÃO INTEGRADA, COMPARTILHADA E PARTICIPATIVA}

\section{Vanessa Gayego Bello Figueiredo}

Arquiteta e urbanista. Doutora em planejamento urbano e regional pela FAU/USP, docente na Faculdade de Arquitetura e Urbanismo da PUC-Campinas, ex-Subprefeita de Paranapiacaba e Pq. Andreense/Santo André

\section{RESUMO}

Um dos desafios mais correntes na gestão de sítios históricos é a busca da simbiose entre a preservação do patrimônio, do ambiente e o desenvolvimento socioeconômico. Abordagens recentes, como a de paisagem cultural, enfocam a interdisciplinaridade e o território como chaves na formulação de políticas integradas que superem dicotomias clássicas, incluindo o distanciamento ainda diametral na gestão dos patrimônios natural, cultural, material e imaterial. Tomando como referência o Programa de Desenvolvimento Sustentável de Paranapiacaba (Santo André-SP), o artigo apresentará como as políticas setoriais foram concebidas e implementadas articuladamente, por meio da descentralização administrativa que, entre 2001 e 2008, viabilizou a bem-sucedida integração entre políticas de preservação cultural, conservação ambiental, turismo comunitário, desenvolvimento social, planejamento urbano e participação cidadã. Ao final, destacam-se os principais legados e lições desta experiência.

Palavras chave: preservação da paisagem cultural, políticas públicas integradas, 


\section{RESUMEN}

Una relación armoniosa entre la conservación patrimonial y el desarrollo socio-económico es un reto siempre presente en la gestión de sitios históricos. Enfoques recientes, como el de paisaje cultural, se centran en la interdisciplinariedad y en el territorio, como claves para la formulación de políticas integradas que superen las dicotomías clásicas, incluyendo el distanciamiento en la gestión de los distintos patrimonios: natural y cultural; material e inmaterial. Tomando como referencia el Programa de Desarrollo Sostenible de Paranapiacaba (Santo André-SP, Brasil), el artículo muestra cómo las políticas sectoriales se diseñaron e implementaron, destacando las enseñanzas extraídas de esta experiencia. A través de la descentralización administrativa se materializó, entre 2001 y 2008, la integración de las políticas culturales, de conservación medioambiental, turismo comunitario, desarrollo social, planificación urbana y participación ciudadana.

Palabras clave: conservación del paisaje cultural, políticas públicas integradas, planificación territorial participativa, turismo comunitario

\section{ABSTRACT}

A harmonic relationship between heritage preservation and socioeconomic development is a challenge there is very present in the historic sites management. Recent approaches, such as the cultural landscape, focus on the interdisciplinarity and the territory as keys in the formulation of integrated policies that go beyond classical dichotomies, including the still diametrical detachment in the management of the natural, cultural, material and immaterial heritages. On the basis of the Paranapiacaba's Sustainable Development Programme (Santo André-SP), the article will present how the sector policies are designed and implemented articulately, highlighting the main legacies and lessons from this experience. From the creation of the Paranapiacaba and Andreense Park Borough in 2001, made it possible to decentralised public management and integrated between the policies of cultural heritage preservation, environmental conservation, tourism, social development, urban planning and citizen participation necessary for the recovery of this precious heritage and the promotion of sustainable development.

Key words: cultural landscape preservation, integrated public policies, participative territorial planning, community tourism 


\section{A VILA FERROVIÁRIA DE PARANAPIACABA}

Implantada no topo da Serra do Mar, numa altitude de 796 metros, a 64 quilômetros da capital paulista, a Vila Ferroviária de Paranapiacaba é um exemplar notável do patrimônio cultural e natural brasileiro. Está inserida na área de proteção aos mananciais de Santo André, região onde se preserva significativos fragmentos de Mata Atlântica, reconhecidos em 1994 pela UNESCO como Reserva da Biosfera do Cinturão Verde de São Paulo.

Paranapiacaba, "local de onde se vê o mar" na linguagem indígena, conserva um significativo acervo tecnológico ligado à ferrovia e testemunhos de um padrão arquitetônico e urbanístico bastante avançados para a época de sua implantação. Essa vila ferroviária se desenvolveu a partir de 1860 com a implantação da ferrovia Santos-Jundiaí, construída pela companhia inglesa São Paulo Railway. Em 1957 a ferrovia e todo seu patrimônio foram incorporados à administração da Rede Ferroviária Federal S.A. A partir dos anos 80 , passou por um intenso período de abandono e degradação, acompanhando o descaso dos governos para com o transporte e o patrimônio ferroviários.

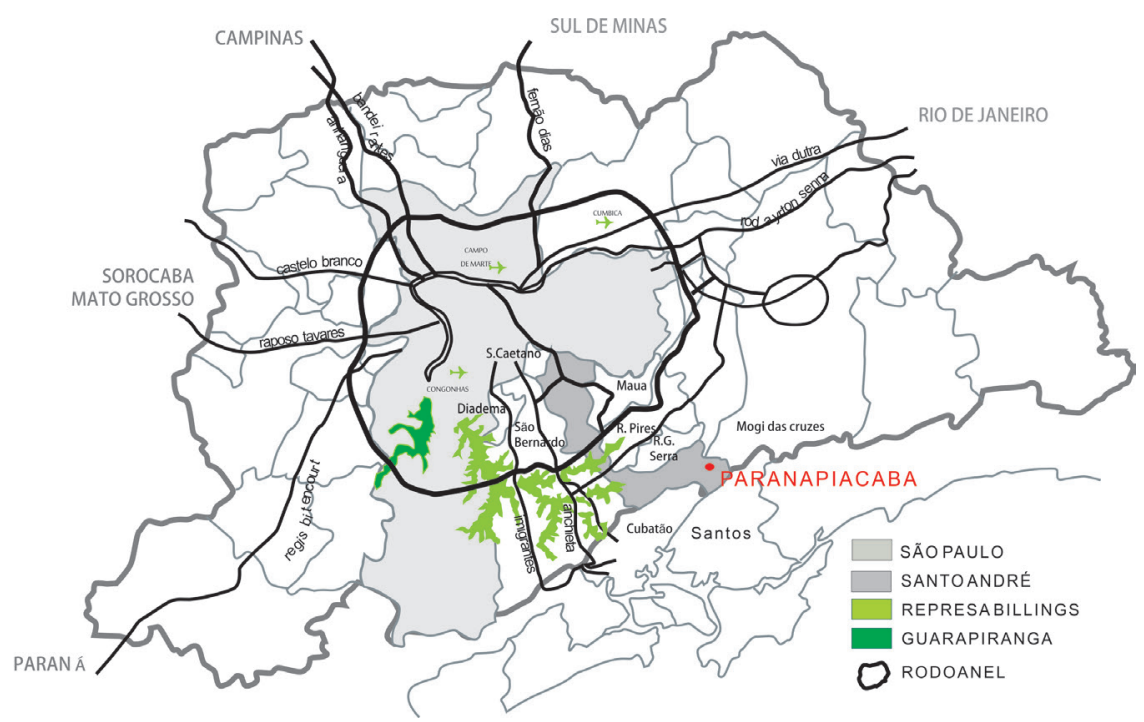


Em 1987, teve seu patrimônio reconhecido pelo órgão estadual, em 2002 pelo nacional (IPHAN) e municipal. Entre 2003 e 2007 foi considerada pela World Monuments Fund (WMF) um dos cem patrimônios mais importantes do mundo em risco. Em 2008, em virtude das políticas de reabilitação saiu da lista da WMF, e tornou-se o primeiro patrimônio cultural paulista e também o primeiro patrimônio industrial brasileiro a compor a lista indicativa do Brasil ao título de Patrimônio da Humanidade da UNESCO. Esta candidatura foi retomada pelo IPHAN em 2014, após o anúncio dos vultosos US\$ 15 milhões em investimentos do Programa Nacional para as Cidades Históricas.

A Vila Ferroviária de Paranapiacaba é composta por três áreas com morfologia urbana bastante distintas: a Parte Alta, com um padrão de ocupação característico do colonial português 247 habitantes (IBGE, 2000); o Rabique, região com alta declividade, grande risco de deslizamentos e ocupações irregulares e a Parte Baixa, com 1.171 moradores. Esta ultima subdivide-se em três áreas: A Vila Velha, local onde foi o acampamento dos ferroviários, com habitações de pau-a-pique e sapé, depósitos e oficinas, assentadas desordenadamente ao longo da Rua Direita; o pátio ferroviário onde encontram-se remanescentes dos sistemas dois funiculares que utilizavam máquinas fixas à vapor tracionadas por cabos de aço em contrapeso. Em 1974 foi instalado o sistema cremalheiraaderência sobre os trilhos do primeiro funicular, ainda em operação para o transporte de cargas; a Vila Nova, ou Martin Smith, adotava padrões urbanísticos correntes na Europa pós Revolução Industrial, a partir de um traçado ortogonal, com ruas largas e hierarquizadas, vielas sanitárias e redes de infraestrutura urbana. A vila operária com suas diversas tipologias em madeira marca a tradição construtiva inglesa, cuja homogeneidade formal contrastava com a extrema hierarquia social da empresa. O tamanho do lote e da casa e seus acabamentos definiam distintas categorias de funcionários: engenheiros, foguistas, maquinistas e alojamentos para funcionários solteiros.

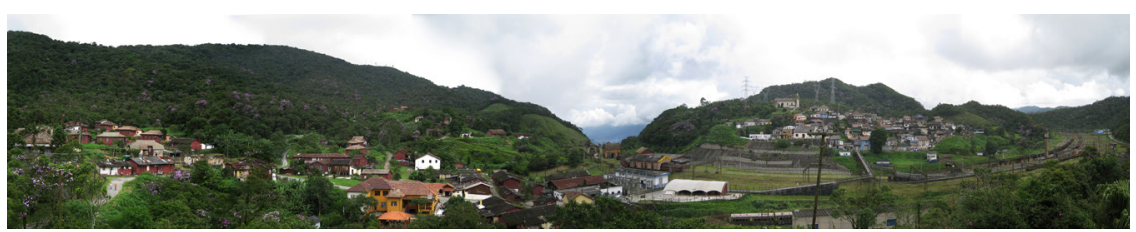

Vista do Castelinho, a casa do engenheiro-chefe: a Parte Alta, o Pátio Ferroviário e a Vila Velha. Foto: Victor Hugo Mori, 2008 
Serra, Vale do Rio Mogi e o trem de carga da MRS Logística descendo no sistema cremalheiraaderência. Foto: Julio Bastos, 2008

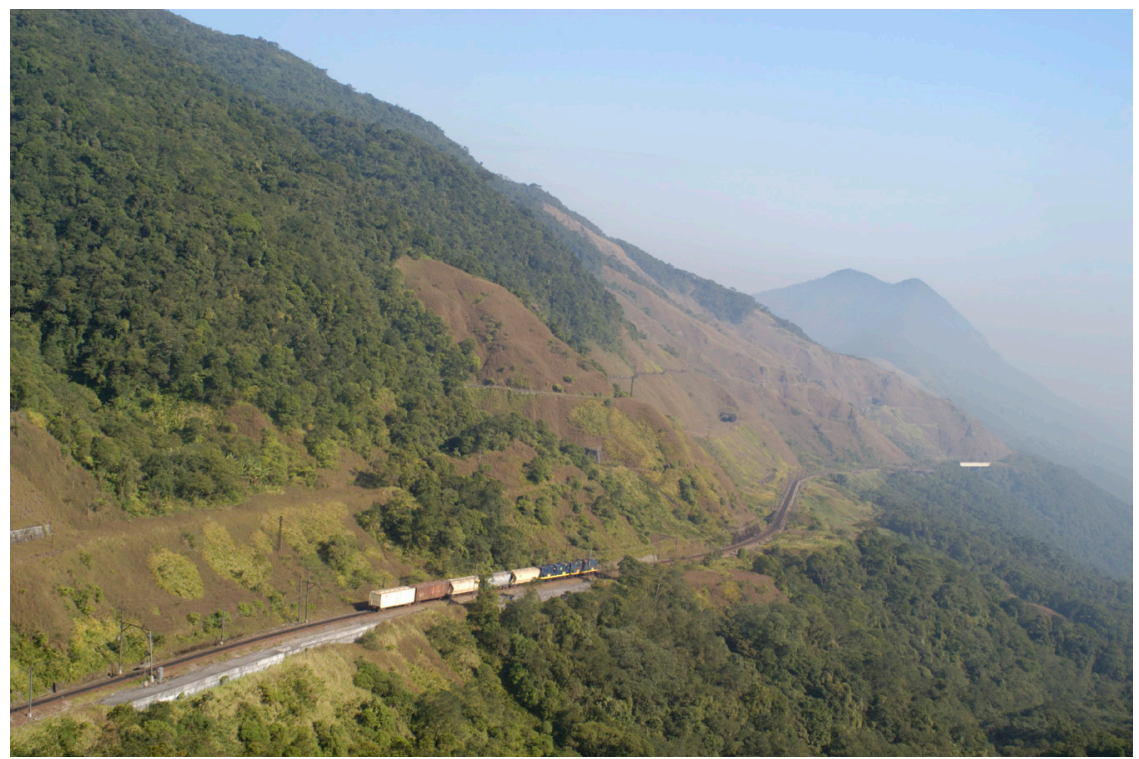

\section{INTEGRANDO POLITICAS: DESCENTRALIZAÇÃO, INTERDISCIPLINARIDADE, INTERINSTITUCIONALIDADE, PARTICIPAÇÃO E TERRITÓRIO}

O isolamento do distrito de Paranapiacaba provocado pelo braço da Represa Billings que corta o município conformou-se no primeiro problema de integração territorial, cujo desafio voltou-se à promoção da descentralização administrativa e dos sentidos de "pertencimento" e identidade dos 6.399 habitantes (IBGE, 2000), cerca de $10 \%$ da população andreense.

O processo iniciou-se em 1989 por meio das "Centrais de Atendimento" (PMSA, 2006). Em 1998 realizou-se o projeto de "Gerenciamento Participativo em Áreas de Mananciais", em parceria com a Universidade British Columbia e a Agência de Desenvolvimento Internacional (Canadá), enfocando o desenvolvimento socioeconômico, a regularização fundiária e alternativas para áreas ambientalmente sensíveis (PMSA, 2004). Em 2001 foi criada a Subprefeitura priorizando a integração da região à cidade; a compatibilidade com a produção de água; a preservação ambiental e cultural; a participação e o turismo comunitário como principal atividade econômica. 
Com a compra da Vila pela prefeitura em 2002, iniciou-se a gestão administrativo-financeira dos imóveis públicos e o Programa de Gestão do Desenvolvimento Local Sustentável, intensificando o processo de recuperação destes patrimônios, compreendidos e gerenciados como "paisagem cultural".

Tal abordagem, utilizada pelo Comitê do Patrimônio Mundial desde 1992 e pela Recomendação R(95)9 (COUNCIL OF EUROPE, 1995) foi recentemente incorporada pelo IPHAN (Carta de Bagé, 2007 e Chancela, 2009). Amplia-se significativamente a noção de patrimônio articulando conceitos e objetos de diversos campos, considerando a interdisciplinaridade e o território como chaves para a superação da fragmentação ainda praticada tanto na concepção quanto na implementação de políticas públicas. Partindo-se de uma concepção integradora da relação homem-natureza e dos patrimônios material e imaterial, adotar a paisagem como patrimônio admite as relações intrínsecas entre abordagens da história, antropologia, ecologia, das artes, entre outras, e suas correspondências no meio físico, urbano, rural ou natural. Essa concepção torna bastante complexa a gestão dos patrimônios, requerendo a reformulação das políticas de preservação vigentes, sobretudo, em sua articulação intersetorial e interinstitucional (FIGUEIREDO, 2014), conforme se verificará na experiência de Paranapiacaba.

A seguir apresentar-se-á estas políticas integradas, sem detalhá-las exaustivamente, com a intenção de construir um panorama geral desta experiência, destacando os principais legados, lições, continuidades e rupturas.

\section{O PLANEJAMENTO URBANO E A PRESERVAÇÃO DO PATRIMÔNIO}

A prática da preservação de sítios históricos urbanos no Brasil vem mostrando que o tombamento, embora cumprindo seu papel na outorga de valor, é um instrumento insuficiente diante das necessidades de preservação de paisagens culturais. Tal abordagem considera a essencialidade da ação integrada do planejamento e gestão territoriais com as políticas ambientais, socioeconômicas e culturais. Desta maneira, o desafio está em conjugar a política de preservação ao processo dinâmico de desenvolvimento das cidades, o que implica necessariamente em não impedir a mudança, mas em direcioná-la na perspectiva do desenvolvimento sustentável.
Máquina fixa do $5^{\circ}$ Patamar dos Novos Planos Inclinados da Serra, 1900. Coleção: SPR Fonte: RFFSA Reprodução: MSAOAG

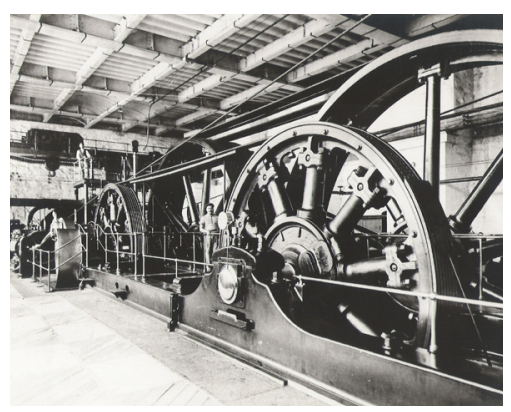


Locobreque com vagões de passageiros e de carga, Raiz da Serra. O motorneiro é Manoel Machado, c. 1950. Foto: Domingos Machado Coleção: Ivete Machado Buosi Fonte: Ivete Machado Buosi Acervo: MSAOAG

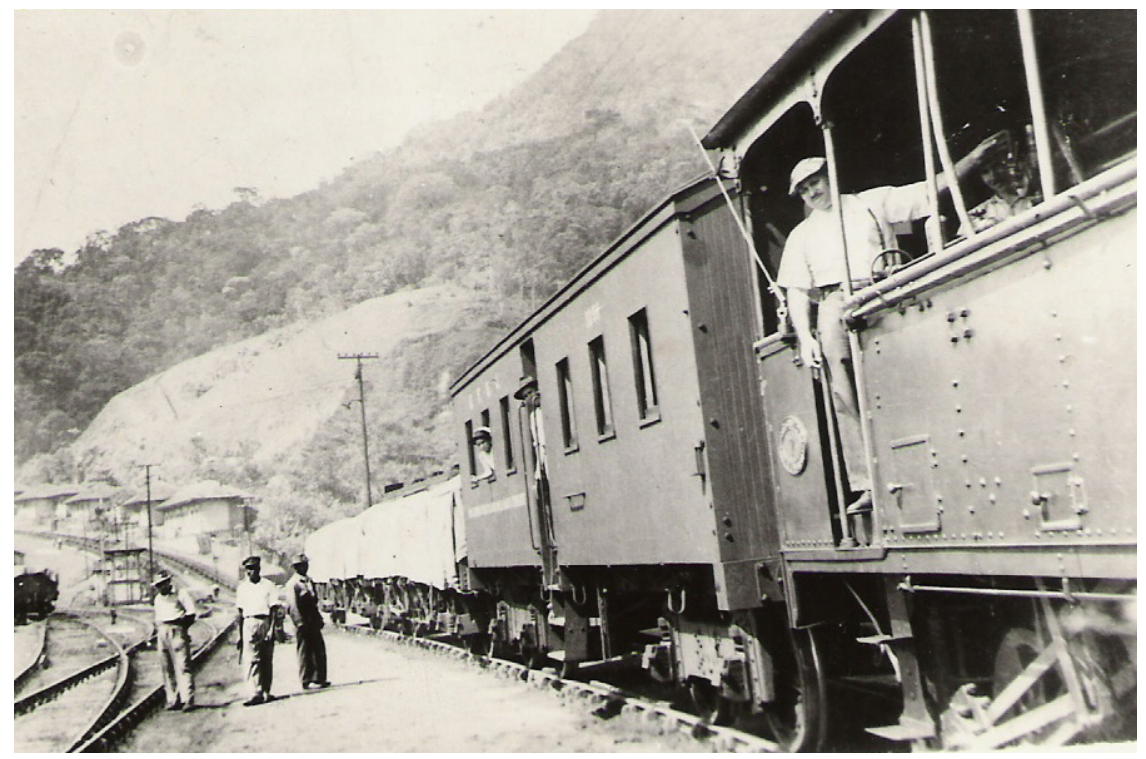

Diante destas preocupações foi instituída a Lei da ZEIPP - Zona Especial de Interesse do Patrimônio de Paranapiacaba, um instrumento que vem sendo considerado inovador pelo Ministério das Cidades e IPHAN ${ }^{1}$, exatamente por articular o planejamento urbano às diretrizes de preservação e gestão da paisagem cultural de Paranapiacaba e demais políticas setoriais.

A ZEIPP foi criada em 2004 pelo Plano Diretor Participativo de Santo André (Lei 8.696) e regulamentada em 2007 (Lei 9.018). Trata-se de uma simbiose entre o que seria um plano diretor local com regramentos de uso e ocupação do território. Constitui-se no principal instrumento de orientação da política de desenvolvimento urbano e gestão territorial da paisagem cultural de Paranapiacaba. Concilia diretrizes de preservação cultural e ambiental ao desenvolvimento do turismo, visando à sustentabilidade do patrimônio edificado, natural e imaterial da Vila, garantindo também a permanência e qualidade de vida dos moradores.

1 Breve matéria sobre a ZEIPP está publicada no site do Ministério das Cidades/Secretaria Nacional de Programas Urbanos/Legislação. A convite do IPHAN- Instituto do Patrimônio Histórico e Artístico Nacional, a lei foi apresentada no I Fórum Nacional de Patrimônio (2009), na mesa "Regulação e Marcos Legais". 


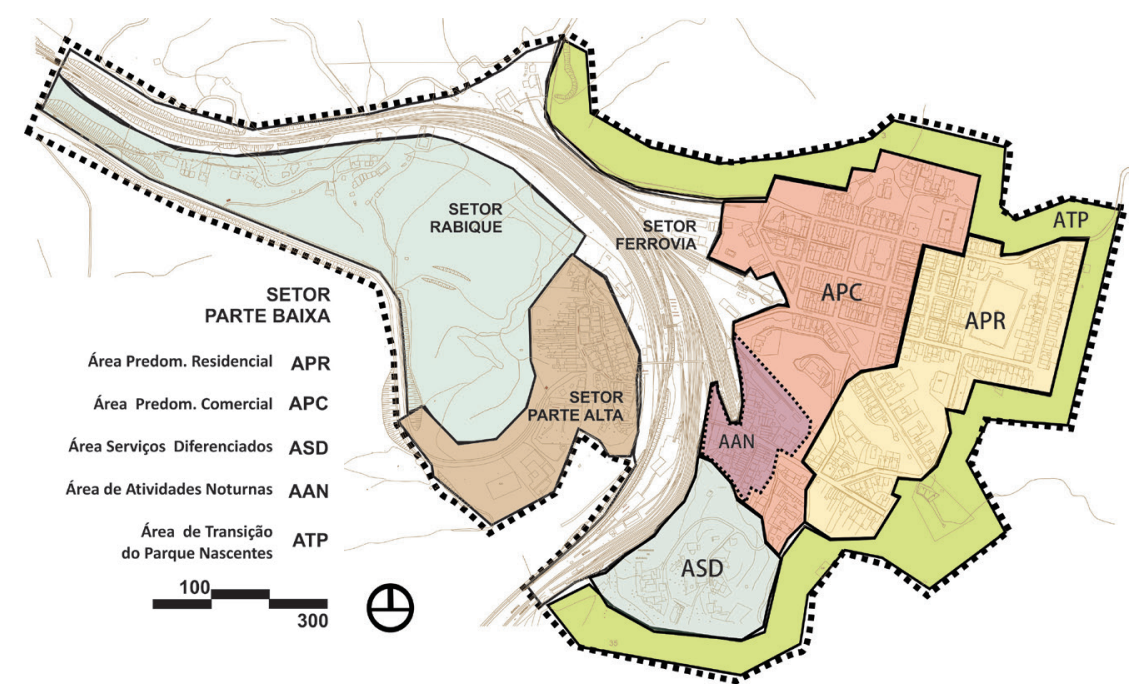

Paranapiacaba: Zoneamento. Mapa: Figueiredo. Fonte: Lei 9.018/07 - ZEIPP

Conforme exigência do Estatuto da Cidade (lei federal 10.257/01), o processo de elaboração do projeto de lei ocorreu de forma participativa, por meio da Comissão da ZEIPP. Reunindo 34 membros, com $50 \%$ da representação para a comunidade local e as outras vagas para representantes dos três órgãos de preservação do patrimônio (Nacional, Estadual e Municipal), do Conselho Municipal de Política Urbana, de universidades e entidades de classe, a comissão garantiu a participação ativa e qualificada dos representantes, capacitados durante o processo. Os técnicos da prefeitura não tiveram assento e atuavam como formuladores de estudos técnicos e mediadores dos debates. Os técnicos dos órgãos de preservação participaram ativamente desempenhando o papel de orientadores e debatedores das propostas.

No que tange especificamente à articulação entre as políticas de preservação do patrimônio e planejamento territorial, esta lei representa também um avanço, tanto no âmbito teóricoconceitual quanto de gestão. A Vila de Paranapiacaba recebeu, através de uma única lei, um conjunto de diretrizes, instrumentos e parâmetros urbanísticos e ambientais específicos à sua realidade e articulados entre si, contribuindo para a institucionalização de uma política adequada às singularidades deste território, em especial à conservação da mata atlântica, 
à produção de água, à preservação de uma vila operária com casario em madeira e à vulnerabilidade social da população residente.

Inicialmente a lei pactua conceitos referentes à preservação, conservação, restauração, reparação, manutenção, atualização tecnológica (retrofit) e adaptação (art.5o), diferenciando- os e propondo uma hierarquização dos diversos tipos de intervenção no patrimônio edificado, visando à desburocratização dos processos de aprovação e o compartilhamento de papéis entre as instituições gestoras, institucionalizando uma prática corrente entre a subprefeitura e os órgãos de preservação.

A ZEIPP ratifica a divisão da Vila em quatro setores de planejamento urbano (Parte Alta, Parte Baixa, Ferrovia e Rabique), reconhecendo suas especificidades históricas, urbanas, paisagísticas e legais. Cria um zoneamento priorizando o uso residencial e definindo áreas para o desenvolvimento das atividades comerciais e turísticas, minimizando os conflitos de vizinhança. Trabalha com o controle de estoques para a regulação das predominâncias de usos, a exemplo da APR - Área Predominantemente Residencial onde o comércio e os serviços de baixa incomodidade (pousadas e restaurantes funcionando até às $22 \mathrm{~h}$ ) é permitido até $20 \%$ dos lotes. Na APC - Área Predominantemente Comercial são permitidos os usos não residenciais até $60 \%$. Fixa também o estoque habitacional em $50 \%$ dos imóveis públicos da Parte Baixa, ou seja, garante em lei a permanência da moradia, evitando possíveis futuros desvios que destinem os imóveis predominantemente para usos turísticos e casas de veraneio. Foram redefinidos também parâmetros para ocupação dos lotes (recuos) e seus limites, taxas de permeabilidade, níveis de incomodidade por emissão sonora, diretrizes para a preservação das edificações e espaços livres e a hierarquização do sistema viário, com o objetivo de salvaguardar o conjunto e as relações urbanas que caracterizam a paisagem da Vila.

Paranapiacaba conta com 334 casas somente na Parte Baixa. Foram selecionados em lei imóveis representativos, designados como "Exemplares de Tipologias Residenciais". O objetivo foi destacar o valor documental e cognitivo do projeto ou construção original, sem que fossem modificados, permitindo que nos demais imóveis fossem realizadas intervenções para adaptação de usos conforme restrições impostas por cada tipo de imóvel.

Estes exemplares foram destinados à visitação pública, compondo o Circuito Museológico, 


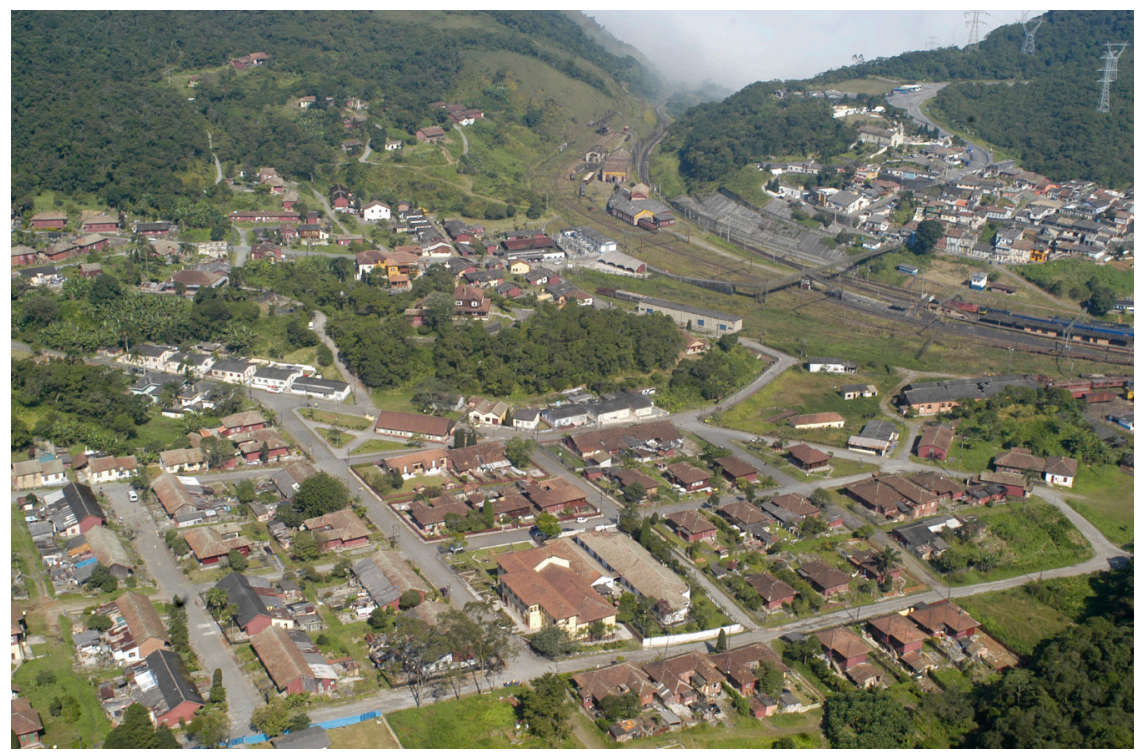

premiado em 2007 pelo IPHAN no "Concurso de Modernização de Museus". Baseado na concepção de "museu a céu aberto", o projeto articula espaços expositivos diversos ao percurso que envolve a percepção da paisagem cultural: a casa "Typo C", conhecida como "Castelinho" ou "Casa do Engenheiro-Chefe", abriga uma exposição sobre a história da Vila; o patrimônio natural é exposto em um exemplar de Casa de Engenheiro; o patrimônio humano está na Casa da Memória, um exemplar da casa "Typo A" (para famílias pequenas de operários); um conjunto de casas "Typo E" (para operários menos graduados) trata do patrimônio arquitetônico e urbanístico; as Casas "Typo D"2 integram o Antigo Lyra da Serra (onde funcionou o segundo cinema do Brasil), atualmente em restauro para abrigar o cineteatro e um espaço para educação patrimonial.

Para os demais imóveis as ampliações funcionais são permitidas, entretanto devem respeitar as relações entre espaços livres e edificados, configurados pelo padrão urbanístico da Vila, preservando a relação entre os recuos, o corpo principal da edificação, o quintal, o sanitário ao fundo do lote e a viela sanitária ao meio da quadra. Isto é, para os imóveis
A Vila Nova (em primeiro plano); o pátio ferroviário e Parte Alta (ao lado direito); a Vila Velha (ao fundo); ao meio o Castelinho (Casa Typo C do EngenheiroChefe). Foto: Julio Bastos/PMSA, 2006

2 Estas nomenclaturas foram utilizadas pelos ingleses quando do plano e projetos originais da Vila (LIMA, 2008). 


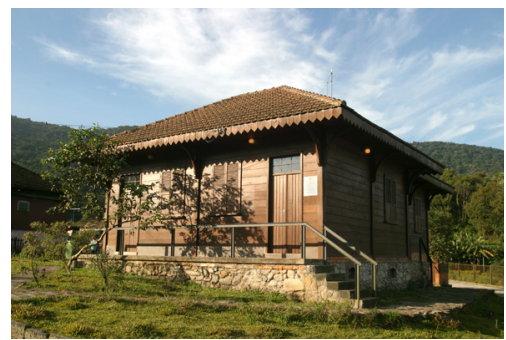

Casa da Memória. Autoria: Heloisa Ballarini, 2007

Cooperativa de Marcenaria em atividade de restauro das Casas Tipo E-CDARQ. Fonte: LIMA, 2008. Fotos: Gilson Lima, 2007

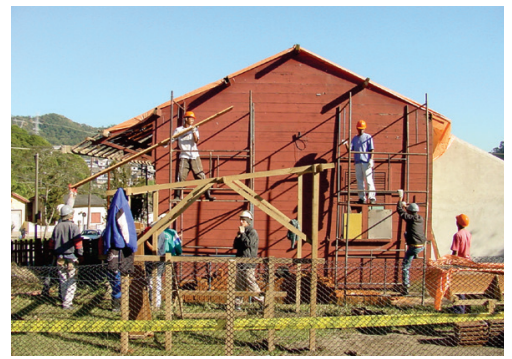

que têm originalmente os banheiros fora da casa será permitida a ampliação para suprir necessidades, como coberturas para lavanderia, desde que esta não una o corpo principal do imóvel ao anexo do sanitário ao fundo e não ocupe os recuos frontais e laterais. Desta forma, superou-se a adoção dos tradicionais níveis de tombamento, compreendidos como uma gradação hierárquica e genérica incoerente à concepção de paisagem cultural.

Foram criados instrumentos de incentivo à preservação e um sistema de fiscalização e penalidades mais rigoroso, embora adequados à realidade local. Visando incentivar a conservação dos imóveis e ter controle sobre a ação dos usuários, eram concedidos descontos na contraprestação aos permissionários que investissem na manutenção, desde que fosse realizada com autorização da Prefeitura, conjuntamente com os órgãos de preservação. Este procedimento de aprovação interinstitucional, que já funcionava desde 2005, foi institucionalizado pela lei.

A ZEIPP garantiu aos empreendedores um instrumento de posse menos precário criando, para os imóveis comerciais, a concessão de uso por 20 anos, renováveis por igual período. Estabeleceu-se ainda um novo instrumento de acompanhamento e democratização da gestão: o Fórum de Paranapiacaba, reunindo, nos mesmos moldes da Comissão da ZEIPP, representantes da prefeitura, dos órgãos de preservação e da comunidade, no debate permanente quanto ao desenvolvimento sustentável da Vila.

A lei é, em sua maior parte, autoaplicável. Apenas alguns artigos necessitaram de regulamentação posterior, como o Fórum (regulamentado em 2008), ou instruções normativas e planos, detalhando informações técnicas que não cabem ao disciplinamento da legislação urbanística, a exemplo dos manuais de arquitetura, paisagismo e dos planos de saneamento, energia e iluminação pública, todos concluídos em 2008.

Paralelamente, a subprefeitura promoveu diversas ações visando à conservação do patrimônio, articulando pesquisa científica, sistemas de informação e documentação, educação e formação profissional. Entre 2004 e 2008, pesquisadores do Centro Universitário Fundação Santo André, com financiamento da FAPESP - Fundação de Amparo à Pesquisa do Estado de São Paulo, modalidade políticas públicas, e apoio da prefeitura, desenvolveram a pesquisa "Diretrizes e Procedimentos para a Recuperação do Patrimônio Habitacional em Madeira na Vila de Paranapiacaba" (LIMA, 2008). Esta pesquisa articulou- 
se às necessidades das políticas públicas municipais e rendeu vários frutos, como a criação de metodologia própria para a inventariação do patrimônio em madeira, a reativação da cooperativa de restauradores, a criação do banco de materiais e a elaboração do Manual de Conservação e Restauro.

Todos estes produtos foram incorporados à ZEIPP como diretrizes permanentes. O objetivo foi constituir documentos-padrão que orientassem os técnicos do poder público a respeito dos procedimentos adequados para intervenções no patrimônio em madeira. Vale ressaltar que este é um dos mais graves problemas enfrentados pelos órgãos de preservação no Brasil. A ausência de diretrizes e parâmetros pré-estabelecidos capazes de orientar intervenções em bens tombados levam a decisões particularizadas, demasiadamente discricionárias e, muitas vezes, antitéticas entre os diferentes órgãos do patrimônio.

O inventário arquitetônico dos imóveis da Parte Baixa foi sistematizado em base digital no "Banco de Dados de Gestão do Patrimônio de Paranapiacaba", articulando as informações arquitetônicas aos dados socioeconômicos e administrativos dos moradores. Este inventário contém informações fotográficas, dados sobre a conservação dos imóveis e levantamento planimétrico, com identificação das tipologias, de anexos existentes e paredes ou materiais originais já retirados ou alterados nos imóveis.

A cooperativa de restauradores formou-se com moradores capacitados para trabalhar especificamente com restauro e conservação em madeira. Até 2008, já havia restaurado um conjunto de quatro casas "Typo E", uma casa de engenheiro incendiada recomposta com o programa de biblioteca pública, os cercamentos de uma quadra e a Antiga Padaria, finalizada em 2010. Além disso, a cooperativa produzia elementos construtivos, como portas, janelas, mãos francesas, beirais e cercas, visando à constituição de um banco de materiais centralizado para reposição adequada de elementos arquitetônicos degradados.

A partir de 2006 promoveram-se cursos específicos de educação patrimonial ${ }^{3}$, cujo módulo básico era oferecido a todos os moradores e os demais módulos (intermediário e avançado) visavam formar monitores culturais.

3 Curso ministrado em parceria com os órgãos de defesa do patrimônio (IPHAN, CONDEPHAAT e COMDEPHAPASA), o Museu de Santo André, o MAE - Museu de Arqueologia e Etnologia da USP, a ABPF - Associação Brasileira de Preservação Ferroviária e a Fundação Santo André/FAPESP.

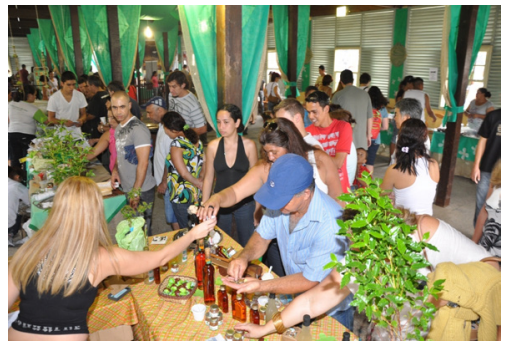

Celebrações em Paranapiacaba: grupo instrumental brasileiro Uakti no Festival de Inverno, 2004. Foto: Beto Garavelo/PMSA, 2010. Festival do Cambuci

Festival de Inverno

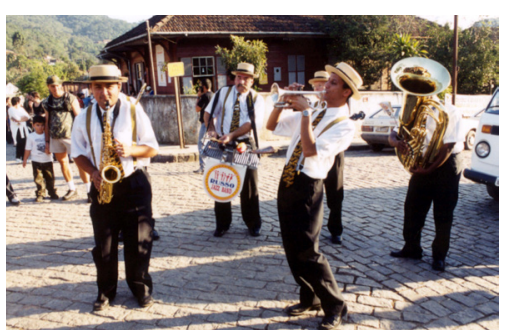


Buscando reverter o processo de degradação sofrido nas décadas de 80 e 90, a Subprefeitura retirou, até 2008, 49 anexos precários e irregulares dos imóveis, $50 \%$ da demanda. O procedimento acontecia quando os imóveis eram devolvidos ou por meio de acordo com os moradores. A lei da ZEIPP estabeleceu que uma ação mais ostensiva fosse iniciada em 2010. Entretanto, a nova administração conseguiu dilatar este prazo e a ação retomar-se-á efetivamente com as obras do PAC-CH a partir de 2015 , visto que estão previstas intervenções em 242 casas.

Por fim, entre 2001 e 2008, foram investidos cerca de 4,5 milhões de dólares em 27 obras de restauração do patrimônio edificado e de espaços livres ${ }^{4}$, além do investimento anual de 82 mil dólares na conservação e manutenção contínua.

\section{O TURISMO SUSTENTÁVEL E A CONSERVAÇÃO AMBIENTAL}

O programa proposto vislumbrava a promoção do turismo de base endógena, onde a comunidade estivesse inserida na rotina da visitação pública, na convivência com o turista e nas atividades e produtos turísticos. Este projeto foi implantado com planejamento e paulatinamente, visando incluir os moradores e evitar possíveis impactos indesejáveis sobre os patrimônios, o ambiente e a rotina e qualidade de vida da população.

A prefeitura utilizava o método do planejamento estratégico situacional e foi estruturando o programa em três etapas. O objetivo da primeira etapa (2001-2004), foi a implantação da atividade turística, com criação de infraestrutura de recepção, alimentação, hotelaria, serviços e produtos turísticos, praticamente inexistentes. Diversos programas incentivaram a inserção da comunidade no turismo, como: o Portas Abertas, o Fog \& Fogão, o Bed and Breakfast e o Atelier-Residência. Todos incentivavam uso misto no imóvel, ou seja, o morador podia abrir um empreendimento voltado ao turismo em sua própria casa. Como incentivo financeiro àqueles que ingressavam no programa foi concedido um desconto de $70 \%$ nas contraprestações. O principal resultado foi um salto de 9 empreendimentos em 2002 para 97 em 2008. Institui-se também a medição da visitação que registrou em 2002 cerca de 41 mil turistas anuais e 220 mil em 2008.

4 Com recursos da prefeitura, da American Express através da World Monuments Fund, da Petrobrás, da FAPESP/Centro Universitário Fundação Santo André e do Ministério do Turismo. 
Em 2003 foi elaborado o "Plano Patrimônio", sistematizando um diagnóstico dos atrativos turísticos e criando a logomarca turística e estratégias de divulgação. Neste momento foram criados dois dos principais produtos turísticos de Paranapiacaba: o Calendário Cultural Anual e o Parque Nascentes. O Calendário Cultural compôs-se de uma mistura que buscava a promoção de três tipos de eventos: aqueles tradicionais já praticados pela comunidade e região; eventos do calendário nacional e eventos criados para atrair público. Desta forma, o ano inicia com a mais tradicional festa brasileira: o carnaval. Em abril há o Festival Gastronômico do Cambuci (fruto típico da Mata Atlântica identificado em uso na culinária em estudos de história oral), seguido da Festa Junina e das comemorações do mês do meio ambiente. Em julho acontece o principal evento do calendário, o Festival de Inverno, responsável por cerca de $50 \%$ da visitação anual. Em agosto há a Festa do Padroeiro, seguida da Semana do Ferroviário, o mês da criança e a Feira de Oratórios e Presépios. Em 2004, aconteceu a primeira Festa das Bruxas e Magos, importante comunidade organizada nacionalmente que tem em Paranapiacaba o locus de suas práticas e tradições em função de suas propriedades místicas. Esta prática alinha-se aquilo que o Comitê do Patrimônio Mundial vem chamando de paisagem cultural associativa. Em 2008 aconteceu o primeiro Festival de Cinema de Paranapiacaba e ambos foram incorporados ao calendário anual de eventos.

O Parque Natural Municipal Nascentes de Paranapiacaba, criado em 2003 é uma Unidade de Conservação com 4,2 km2, oferecendo trilhas, arborismo e interpretação ambiental na mata. Faz divisa com mais duas UCs: a Reserva Biológica do Alto da Serra de Paranapiacaba e o Parque Estadual da Serra do Mar. Tornou-se, em 2008, uma das áreas mais conservadas da Reserva da Biosfera do Cinturão Verde de São Paulo, compondo um extenso corredor ecológico que envolve 73 municípios, cujo objetivo comum é a conservação e gestão integrada da biodiversidade e dos ecossistemas da Mata Atlântica.

O Parque tem importante contribuição na formação dos corpos hídricos que alimentam o reservatório Billings. Até 2008 percorreram suas trilhas 90.000 visitantes, acompanhados de monitores ambientais formados pelo programa de turismo, promovido pela Subprefeitura em parceria com o Instituto Florestal. Como o Parque é fechado, para garantir o acesso dos moradores, a Subprefeitura criou o projeto "Amigos do Parque", com emissão de 300 carteirinhas. Aos grupos de baixa-renda e escolas públicas municipais eram oferecidos 
Maria-fumaça operando no pátio de Paranapiacaba. Foto: Eduardo Pin, 2009

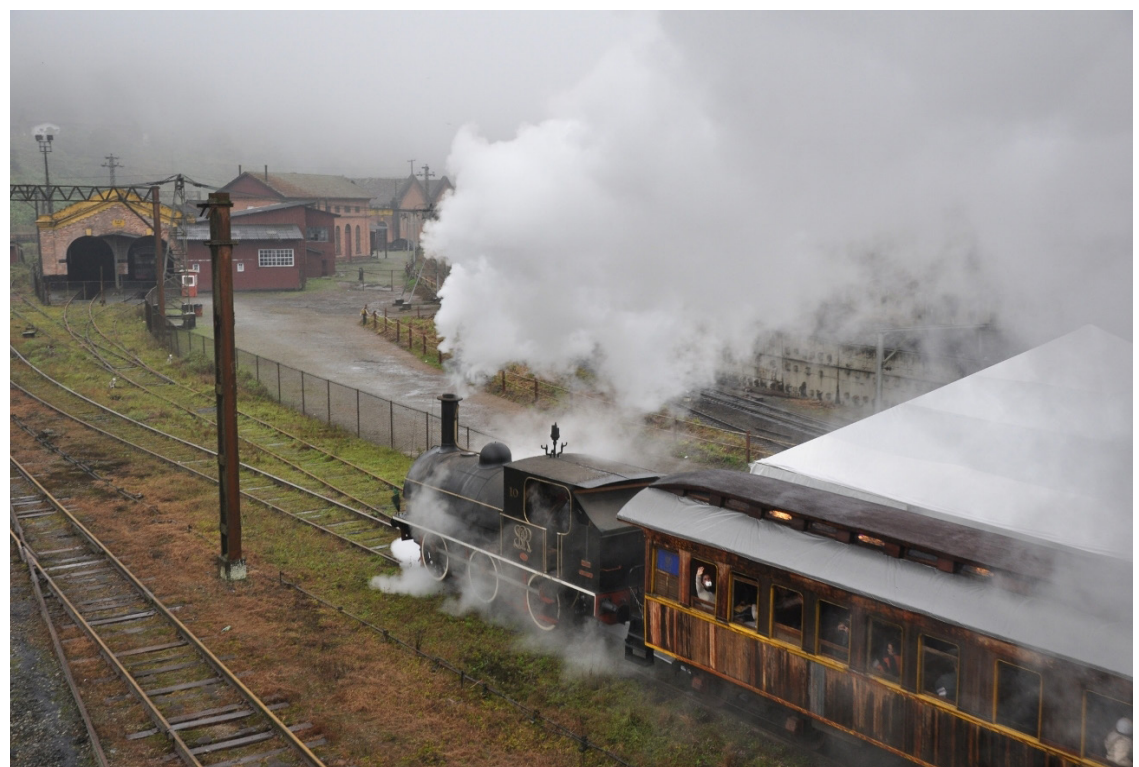

600 atendimentos gratuitos mensais. Ocorrem também provas de turismo de esportes e aventura, como a corrida de montanha e o trekking. Em 2004 foi publicada a primeira edição do "Atlas do Parque", com estudos sobre os aspectos naturais. Em 2008 foi publicada a segunda edição, aprofundando estudos e propostas para o Plano de Manejo.

A segunda etapa do programa de turismo sustentável (2005-2008), preocupou-se com a qualificação dos empreendimentos abertos, com a organização das atividades urbanas no território (ZEIPP) e com a integração definitiva das políticas setoriais. Neste contexto, foram criados o PQST - Programa de Qualificação dos Serviços Turísticos, oferecendo diversos cursos de educação ambiental, patrimonial, profissionalizante, de línguas estrangeiras, culinária, cooperativismo e empreendedorismo. Estes cursos formaram, até 2008, 50 monitores ambientais e 30 culturais. A participação no PQST era facultativa, mas previa um sistema de avaliação através da Certificação 5o. Patamar que graduava os empreendimentos entre um e cinco vagões ferroviários substituindo a tradicional graduação em estrelas. Em 2005 foi feita a primeira certificação e em 2008 a segunda certificação, possibilitando a avaliação periódica da qualidade dos serviços turísticos e da participação 
da comunidade nos cursos e projetos oferecidos, incentivando a responsabilidade de cada um na construção do projeto coletivo.

O Plano Patrimônio foi revisado em 2007 com base nas diretrizes da ZEIPP, gerando o PDTUR - Plano de Desenvolvimento Turístico Sustentável. O PDTUR reavalia os atrativos e produtos turísticos, bem como os segmentos a serem priorizados. Paranapiacaba passa então a focar quatro segmentos: o turismo cultural, o ecoturismo, o turismo pedagógico e o turismo de qualidade de vida. Trabalha-se, como segmentos secundários, o turismo de esporte, aventura e eventos. O PDTUR estabeleceu um plano de infraestrutura turística, um plano de comunicação e um plano operacional.

A partir de 2007, com a sanção da ZEIPP, iniciou-se a preparação para a terceira fase do projeto que compreenderia a formalização e regularização dos empreendimentos turísticos. Este processo visava a adequação dos empreendimentos às normas legais, como as da vigilância sanitária, do código de obras, além da formalização do trabalhador. No entanto, esta etapa não foi concluída devido à troca da administração municipal em 2009.

Durante todo tempo buscou-se parcerias para viabilizar a volta do trem à Paranapiacaba, desativado em 2002. Em 2006 viabilizou-se a implantação da Maria-fumaça no pátio ferroviário e em 2008 foi assinado um termo de cooperação entre a Prefeituras de Santo André e Jundiaí, a Secretaria de Transportes do Governo do Estado de São Paulo, a Companhia Paulista de Trens Metropolitanos, o IPHAN e Associação Brasileira de Preservação Ferroviária para o Trem Expresso Turístico. No mesmo ano foi realizada a viagem inaugural entre a Estação da Luz (São Paulo) e Jundiaí e Luz-Mogi das Cruzes. Em 2010 teve início a operação Luz-Paranapiacaba. Todos os trechos têm como guias de turismo os monitores formados em na Vila.

\section{O DESENVOLVIMENTO SOCIAL E A PARTICIPAÇÃO CIDADÃ}

Entre 2001 e 2008, implantou-se um modelo de gestão democrática e participativa que trouxe os moradores para a linha de frente das decisões locais. Uma gestão que não se constrói de forma centralizada, mas ancorada em redes que envolvem a participação organizada de diversos atores locais e cujo centro de decisões está na própria Vila, com envolvimento

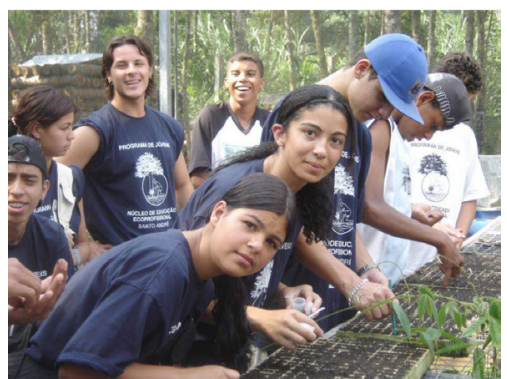

Programa de Jovens. Fonte: PMSA/Subprefeitura, 2005 
do poder público, de instituições afins, como órgãos de preservação, de política urbana e ambiental, dos moradores e interessados.

No entanto, a implantação deste novo modelo encontrou barreiras que exigiram dos condutores constantes revisões no processo e habilidades para transpô-las. Estas dificuldades passavam pela descrença dos moradores em relação ao poder público, durante muito tempo ausente, e pelo rompimento de privilégios estabelecidos ao longo dos anos com lideranças negativas que usufruíam benefícios com o estado de desordem física, social e institucional encontrado (MORETTO, 2004).

Assim, a implementação destas políticas foi realizada com a comunidade, não raro com demasiado debate e conflito inerente ao processo democrático e ao estabelecimento de uma nova ordem socioinstitucional, com participação de um poder público comprometido com o desenvolvimento local sustentável.

Diversas instâncias participativas foram criadas, como o Orçamento Participativo e os conselhos temáticos, até instâncias específicas, como o Conselho de Representantes. Com a compra da Vila foi criado um fundo público para administrá-la e receber as contraprestações pagas pelos permissionários. O FUNGEPHAPA - Fundo de Gestão do Patrimônio Histórico de Paranapiacaba - recebe recursos provenientes da utilização de espaços institucionais, do uso comercial da imagem da Vila e de instituições financiadoras. A cada dois anos era realizada a renovação contratual e as irregularidades encaminhadas às sanções administrativas cabíveis, com três etapas para acordo de dívidas e, em último caso, para reintegração judicial de posse. Até 2008 foram executadas 24 reintegrações, em sua maioria daqueles que se recusaram a reconhecer a propriedade pública e os que estavam envolvidos com ilegalidades, como tráfico de drogas, prostituição infantil e furtos. Todos os que tiveram de deixar suas casas receberam aluguel social de seis meses.

Em 2008, o FUNGEPHAPA, que era gerido deliberativamente com a comunidade por meio do seu conselho, teve sua receita incrementada em $76 \%$ em relação à 2002 , com arrecadação anual de 340 mil dólares (PMSA, 2008). Estes recursos eram utilizados para a conservação dos imóveis, da reserva natural, para os cursos e a promoção do turismo.

Para responder melhor aos anseios da comunidade, a administração sentiu, durante o processo, a necessidade de criar instâncias mais específicas de participação, enfocando 
temas de maior interesse e demanda, como: os Fóruns de Monitores, de Empreendedores, as Comissões de Festejos e da ZEIPP. Estes organismos de gestão participativa visavam integrar os diferentes saberes e buscar soluções e alternativas conjuntas aos problemas do cotidiano, programas e planos, envolvendo a co-responsabilidade da comunidade nas decisões e políticas implementadas.

Por outro lado, estes sistemas de participação fomentavam permanentemente a organização e o protagonismo comunitário, potencializando uma estrutura de governança local, cujo objetivo fora também garantir a continuidade da preservação para além da ação direta da administração pública, isto é, a partir do próprio engajamento social.

Além destes mecanismos de participação, a comunidade foi incentivada a investir em sua qualificação e geração de renda. Dentro do PQST, foram promovidos cursos profissionalizantes, fomentando a formação de grupos por meio do cooperativismo ou associativismo. Foram ministrados cursos de economia solidária, carpintaria, marcenaria, restauro em madeira, artesanato em cerâmica, xilogravura, gastronomia, eletricista, pedreiro e encanador. Em 2008 estavam trabalhando a Cooperativa de Restauro em Madeira e três associações de serviços turísticos: a AMA (Associação de Monitores Ambientais de Paranapiacaba); a ECOVERDE e a ECOPASSEIOS. Estavam em formação a cooperativa de gastronomia e a associação dos artesãos. Outros cursos buscavam a formação continuada e aperfeiçoamentos para monitoria e ações culturais, como o de "Aprendizado Seqüencial e Vivência na Natureza" e o de "Memória Oral", para a formação dos "Agentes da Memória", cuja primeira pesquisa constituiu a exposição apresentada na Casa Fox.

Investiu-se especialmente na formação e inclusão de jovens por meio do Programa de Jovens da Reserva da Biosfera (PJ) e do Agente Jovem. Desenvolvido em parceria com o Instituto Florestal e a UNESCO, o PJ buscava, além da formação integral de adolescentes entre 14 e 21 anos, a capacitação para monitoria ambiental, ecoturismo, manejo florestal, agroindústria artesanal e arte e reciclagem.

Até 2008 o programa atendeu cerca de 220 jovens trabalhando a autoestima e a formação de caráter, além de contribuir para inseri-los no mercado. Até 2008, 14 jovens haviam sido contratados para atuarem como monitores do Parque Estadual Caminhos do Mar, outros 20 atuavam como monitores ambientais em Paranapiacaba e 100\% tiveram oportunidades de 
trabalho durante os eventos turísticos anuais. Cinco continuaram os estudos nas faculdades de biologia, gestão ambiental, administração e educação física. Em 2006 foi implantado o viveiro e horta experimental, financiados pelo Banco Mundial (PMSA,2008).

Paralelamente, o programa Agente Jovem, em parceria com o Governo Federal, proporcionava a formação socioambiental de jovens entre 14 e 17 anos para toda região de mananciais. Da Vila formaram-se 40 alunos, dos quais 13 receberam bolsas no valor de US\$ 30,00 ao mês.

Para promover a inclusão de moradores que não tinham condição socioeconômica de abrir empreendimentos sozinhos foi criado o "Entreposto de Arte e Artesanato" e o "Espaço Gastronômico". Primeiramente o espaço cedido como sede dos projetos foi o Antigo Mercado e em 2006 receberam dois imóveis para suas atividades. Aos empreendedores moradores da Vila foi concedido o desconto de $70 \%$ da contraprestação, pois esse projeto envolvia também moradores da Parte Alta e da região.

Em caso de constatação de situação de risco social, isto é, grandes famílias em casas pequenas, várias famílias subdividindo o mesmo imóvel ou aluguel incompatível com a renda familiar, ou risco ambiental (geotécnico, instabilidade estrutural ou insalubridade sanitária), a Subprefeitura procedia ao remanejamento destas famílias para outros imóveis que proporcionassem uma situação socioambiental mais adequada.

Ademais, a população de baixa renda estava inserida nos programas de transferência de renda. O Bolsa Família, o Família Andreense e o Renda Cidadã atendiam 32 famílias na Vila e 320 na região.

Visando a avaliação e monitoramento das políticas sociais, em 2005 realizou-se um cadastro socioconômico e cultural completo dos moradores e pesquisas pontuais em $2007 \mathrm{e}$ 2008. Alguns indicadores confirmaram a promoção do desenvolvimento local (LUME, 2000; MORETTO, 2004; PMSA, 2008):

A renda média individual aumentou em $77,58 \%$, de US\$ 85 em 2001 para US\$ 150 em 2005; os monitores ambientais e culturais ganhavam um valor médio de US\$340 mensais na alta temporada; o desemprego diminuiu de 61\% em 1999 para 30\% em 2005 e para $16 \%$ em 2008; os empreendimentos cresceram de apenas 9 em 2001 para 97 em 2008 e 90\% 
deles eram de moradores da Vila; a movimentação financeira anual média declarada pelos empreendedores subiu mais de $3.000 \%$, de US\$ $18 \mathrm{mil} / \mathrm{ano}$ em 2002 para US\$ $565 \mathrm{mil} / \mathrm{ano}$ em 2007. Houve também aumento nos níveis de escolaridade, o 20 grau completo subiu de $20,21 \%$ em 1999 para $56,65 \%$ em 2005 e superior de $2 \%$ para $5 \%$ no mesmo período. Um destaque está na opção de muitos jovens em cursar o 30 grau relacionado às atividades turísticas ou ambientais.

\section{LEGADOS E LIÇÕES, CONTINUIDADES E RUPTURAS}

No âmbito deste amplo programa de desenvolvimento local sustentável, baseado na integração entre políticas públicas e no debate permanente entre comunidade e instituições, a experiência de Paranapiacaba enfrentou premissas e desafios consagrados em reflexões acadêmicas e, por seus resultados e conquistas, enfatiza-se como um modelo de gestão não somente necessário às cidades, mas possível às administrações públicas locais. Por isso, vem sendo considerado inovador por diversas instituições nacionais, como o IPHAN, o Ministério das Cidades e a Reserva da Biosfera do Cinturão Verde de São Paulo, e internacionais, como o Programa World Heritage Studies da Brandenburg University of Technology na Alemanha e o Laboratório Internacional de Paisagens Culturais da Universidade Politécnica da Catalunha. Assim, dentre os principais legados e lições deixados por esta experiência há de se destacar dez:

O primeiro, de fundamental importância para a concepção e funcionamento do programa, é a existência de uma estrutura de gestão descentralizada, com autonomia administrativa e orçamentária. Isto significa o reconhecimento das especificidades do território, a proximidade de interlocução com sua população, a integração de políticas gerenciadas dentro de uma mesma estrutura organizacional e corpo técnico interdisciplinar e independência dos setores centralizados das administrações que não têm a região como prioridade.

O segundo consiste na implantação de um sistema permanente de planejamento e avaliação. No presente caso, utilizou-se o método do planejamento estratégico situacional, instrumento que possibilitou a constante revisão das políticas, reconhecendo e superando problemas, adequando metas, incorporando oportunidades, integrando ações das diversas áreas e aprimorando resultados. 
O terceiro destaque está na importância da integração das políticas setoriais ancorada no propósito de construir a interdisciplinaridade. Esta disposição do corpo técnico da subprefeitura foi fundamental para o êxito dos programas, projetos e ações.

O quarto está no sistema de participação qualificada, que por um lado capacita a comunidade para a discussão e por outro potencializa a formação de uma rede de atores e lideranças comprometidas com as políticas implementadas.

O quinto ponto refere-se à utilização dos recursos naturais e culturais, de forma sustentável, a favor do desenvolvimento socioeconômico local, verificado nos indicadores qualitativos e quantitativos apresentados.

O sexto refere-se à política de inclusão social estrategicamente desenvolvida em etapas, alinhada a cada momento de compreensão e condições socioeconômicas da comunidade, porém exigindo sua co-responsabilidade. Isto é, reconhecendo um primeiro momento de tutela, incentivo e adesão ao programa, ou, literalmente, "fornecendo o peixe"; um segundo momento exigindo a qualificação dos participantes e suas responsabilidades no processo de construção coletiva do projeto, "ensinando a pescar", e depois emancipando-os através da formalização (todavia incompleta).

O sétimo ponto ressalta a importância do tripé: planejamento, educação e fiscalização. Apesar de todo investimento em educação (ambiental, cultural, profissionalizante, elevação escolar) e planejamento (territorial, participativo e das políticas setoriais), estes não se sustentam sem a fiscalização, que cumpre um papel também pedagógico na medida em que disciplina a ação humana em prol dos interesses comum e difuso.

O oitavo mostra que a preservação cultural requer muito mais que ações voltadas ao restauro, ainda mais em se tratando do enfoque territorial e integrado evidenciado pela abordagem da paisagem cultural. As dimensões social, urbana, ambiental, econômica e política não podem ser desconsideradas pelos órgãos responsáveis. Contudo, como não há no Brasil, ainda, um único órgão que tenha competência para tratar todas estas dimensões, há de se buscar o compartilhamento interinstitucional.

O nono ponto destaca exatamente a importância desta articulação interinstitucional. No caso da gestão ambiental, diversos projetos eram desenvolvidos conjuntamente com o Governo 
do Estado, o Instituto Florestal, o Comitê de Bacias e a Reserva da Biosfera (UNESCO), observando as diretrizes nacionais (resoluções CONAMA). No caso da preservação cultural, embora esta seja uma experiência pontual, o compartilhamento conduzido a partir do esquema de aprovação conjunta de projetos, bem como dos processos de elaboração e implementação da ZEIPP, possibilitou a articulação de diretrizes de preservação entre os três órgãos de preservação. Todavia, é imprescindível reconhecer que a consolidação deste novo arranjo institucional não se dará por meio da disposição e das ações dos municípios por mais profícuas que sejam. Estes desafios devem ser encampados e conduzidos por meio da construção de um arcabouço legal que institua o Sistema Nacional de Patrimônio, possibilitando a ação compartilhada e corresponsável nos três níveis de governo.

Por fim, é importante considerar que a partir de 2009, devido à ruptura ocorrida com a troca do governo municipal, houve uma desarticulação da gestão local em função, sobretudo, da ausência de plano de governo, da inexperiência do novo grupo gestor, da extinção da subprefeitura e da estrutura de participação. No entanto, embora seja perceptível ao visitante o desmantelamento do programa, é possível constatar a sobrevivência de alguns projetos e instrumentos que foram capazes de consolidar parte das políticas implementadas.

Primeiramente há de se destacar a permanência de instrumentos legais, como a ZEIPP, a Unidade de Conservação e os contratos vigentes para obras de restauro. A existência do Parque Nascentes e seu Plano de Manejo, cuja segunda etapa foi continuada e concluída em 2011, orienta a conservação ambiental e ecoturismo sustentável. Já a ZEIPP, embora com morosidade em sua aplicação e equívocos de interpretação, garantiu a ordenação da atividade turística e a conservação do uso residencial, bem como os critérios gerais de preservação.

Há de se pontuar também o investimento na capacitação dos recursos humanos dentro da proposta de desenvolvimento endógeno, pois o cotidiano do turismo foi efetivamente tocado pelos monitores culturais e ambientais, pelos empreendedores qualificados e instituições organizadas na administração anterior, visto que o quadro de funcionários públicos habilitados a conduzir o projeto foi desmobilizado. A Cooperativa de Restauro que sobreviveu, num primeiro momento, devido aos contratos em execução, foi desagregada pela nova administração, firmada no propósito da desmobilização das redes e organizações sociais fomentadas anteriormente. Todavia, devido à escassez de mão-de-obra qualificada 
para o restauro em madeira, os trabalhadores da cooperativa foram subcontratados pela empresa vencedora da licitação do restauro do Antigo Lyra da Serra em 2011. Obra que foi paralisada em 2012 em razão de problemas de gestão e será retomada em 2015 através do PACCH.

Outros sobreviventes foram os projetos que se consolidaram, fincando raízes na rotina, no desejo e na memória da comunidade e dos visitantes frequentes, tornando-se tradicionais, como o Festival de Inverno, as trilhas de ecoturismo e o Festival do Cambuci que, por ação da Incubadora de Projetos Sociais da Prefeitura de São Paulo, tornou-se regional em 2009, envolvendo oito cidades. O Circuito Museológico continuou existindo, contudo, a visitação completa do roteiro realizava-se mediante agendamento prévio, pois os monitores, sem apoio da prefeitura, não conseguiam manter constantemente os espaços expositivos abertos.

Por outro lado, embora tenha sido fundamental o investimento e o retorno dos processos de participação durante a gestão, constatou-se que ele não foi capaz de gerar empoderamento permanente da população e manter a rede de atores comprometidos por ele potencializada. Tanto as instituições organizadas quanto os cidadãos individualmente acuaram-se diante do absolutismo do novo governo e das ameaças constantes de despejo, processo que induziu o renascimento de lideranças negativas que, democraticamente, ainda participavam do processo.

Esta experiência recoloca em pauta o último ponto a destacar: a capacidade empreendedora e articuladora do poder local, obviamente, no âmbito de suas competências. Diante do processo e resultados angariados pelo programa e dos efeitos imediatamente nefastos do desmonte desta política, cabe uma reflexão profunda sobre o papel do poder local. Tais efeitos podem ser verificados pela diminuição da visitação turística que fez baixar em até $70 \%$ o movimento ${ }^{5}$, gerando o fechamento oficial de 18 estabelecimentos e deixando muitos imóveis desocupados entre 2009 e 2012. Por outro lado, tal fato evidencia a incapacidade dos órgãos de preservação cultural em agir sobre esta realidade. Enquanto o órgão municipal teve sua ação tolhida pelo próprio governo local, o federal e estadual voltaram a

5 Conforme revela a reportagem, a Vila de Paranapiacaba é retrato do descaso. [internet]. Santo André: Jornal Diário do Grande ABC. Disponível em: <http://www.dgabc.com.br/News/5847239/vila-de-paranapiacaba-e-retrato-do-descaso. aspx>. Acesso em: 05 de fevereiro de 2012, e constatação da autora em visita à Vila. 
se distanciar da gestão e do cotidiano citadino, embora não faltassem denúncias e mesmo a interferência do Ministério Público em alguns descasos mais graves com relação aos cuidados com os bens reconhecidos.

Todavia, o último pleito eleitoral revelou a insatisfação dos andreenses ao recolocar parte do grupo político anterior no governo. Porém, este estuda com vagareza a recriação da subprefeitura e tenta rearticular gestores, empreendedores e a comunidade que, juntos, implantaram o programa em tela.

Do sistema político condutor das continuidades e rupturas há pouco a dizer, vale considerar apenas que este é um processo à parte, descolado da gestão administrativa e que sofre efeitos subitâneos de fatores conjunturais. Ademais, faz parte do processo democrático a interrupção e a continuidade, assim como a agenda de prioridades eleita a cada pleito. Parafraseando Churchill, se "a democracia é o pior sistema de governo, à exclusão de todos os demais", deixemos, pois, os demais na gaveta e continuemos a trilhar o intrépido caminho das escolhas e consequências. 


\section{REFERÊNCIAS BIBLIOGRÁFICAS}

COUNCIL OF EUROPE. (1995). Recommendation No. R (95) 9 of the Committee of Ministers to Member States on the Integrated Conservation of Cultural Landscape Areas as Part of Landscape Policies, 1995. $<$ https://wcd.coe.int/wcd/>. (Consulta: 11/10/2011).

FIGUEIREDO, V.G.B. (2014). "Da Tutela dos Monumentos à Gestão das Paisagens Culturais Complexas: inspirações à política de preservação cultural no Brasir'. Tese de Douramento. São Paulo: FAU USP.

FIGUEIREDO, V.G.B.; RODRIGUES, R. (2014). "Paranapiacaba: um patrimônio para a humanidade". São Paulo: Editora Marquise.

LIMA, G.; AZEVEDO, M; PASSARELLI, S. (2008). "Diretrizes e Procedimentos para a Recuperação do Patrimônio Habitacional em Madeira na Vila Histórica de Paranapiacaba". Relatórios de Pesquisa FAPESP/ PMSA/ Fundação Santo André. Santo Andre: s.n.

LUME (Laboratório de Urbanismo da Metrópole). (2000). Plano de Desenvolvimento Sustentável da Vila de Paranapiacaba - SANTO ANDRÉ. Etapa 2 - Produto Final. São Paulo: FAUUSP.

MORETTO, M. (2005). "Protagonismo comunitário em Paranapiacaba: o impacto das ações governamentais no desenvolvimento sócio-econômico-comunitário da Vila de Paranapiacaba no período de 2001 a 2004". Dissertação (mestrado). Universidade de São Caetano do Sul, São Caetano do Sul.

PREFEITURA MUNICIPAL DE SANTO ANDRÉ/SUBPREFEITURA DE PARANAPIACABA E PQ. ANDREENSE (PMSA/SUB). (2006). Memorial da ZEIPP - Zona Especial de Interesse do Patrimônio de Paranapiacaba. Santo André: s.n.

Relatórios de Gestão do Departamento de Paranapiacaba 2001-2008. Santo André: s.n. 2008.

PMSA; AGÊNCIA CANADENSE PARA O DESENVOLVIMENTO INTERNACIONAL. (2004). Desenvolvimento Econômico Comunitário e Turismo para Inclusão Social - Projeto GEPAM. Vol 5. São Paulo: Annablume. 